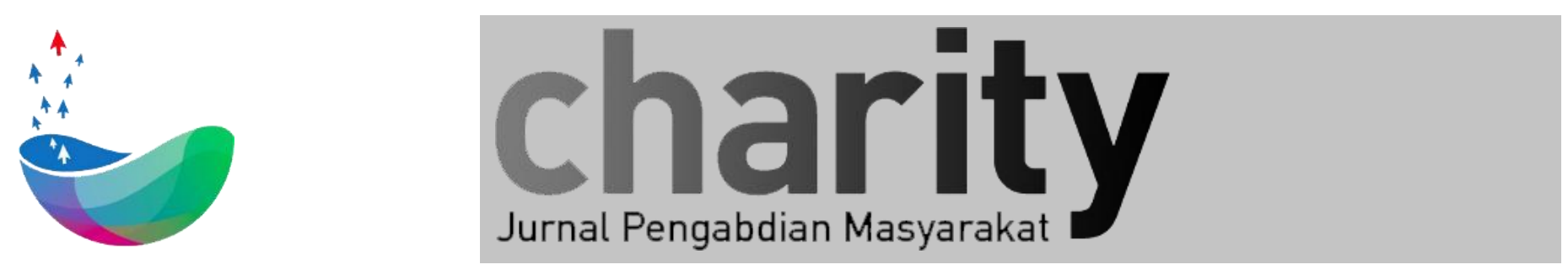

\title{
Prospek dan Keefektifan Penggunaan Google Classroom untuk Pembelajaran: Evidence dari SMP Pajajaran 1 Bandung
}

\author{
Deni Saepudin ${ }^{1}$, Didit Adytia ${ }^{2}$, Kemas Muslim Lhaksmana ${ }^{3}$ \\ 1,2,3 Program Studi Informatika, Fakultas Informatika, Universitas Telkom \\ * denisaepudin@telkomuniversity.ac.id, adytia@ telkomuniversity.ac.id, kemasmuslim@telkomuniversity.ac.id
}

\section{INFO ARTIKEL}

Diterima 10 Februari 2021

Direvisi 22 Agustus 2021

Disetujui 28 Agustus 2021

Tersedia Online 31 Agustus 2021

\begin{abstract}
ABSTRAK
Akibat pandemi Covid-19, masyarakat diminta untuk menjaga jarak fisik (physical distancing) untuk mencegah penularan. Salah satu konsekuensi dari keharusan menjaga jarak fisik ini adalah proses pembelajaran tidak dilakukan di sekolah, namun dilakukan dari rumah melalui media daring. Namun, belum semua sekolah siap melaksanakan pembelajaran daring. Salah satu faktor ketidaksiapan pembelajaran daring adalah pengetahuan/keterampilan guru dalam memanfaatkan media pembelajaran daring. Ada beberapa media online yang dapat digunakan untuk proses pembelajaran daring, salah satunya adalah Google Classroom. Dengan keterampilan para guru dalam memanfaatkan Google Classroom, proses pengajaran daring masih dapat berlangsung meskipun dengan banyak keterbatasan, baik keterbatasan perangkat maupun keterbatasan jaringan. Sampai saat ini, pandemi Covid-19 masih berlangsung dan belum diketahui kapan berakhir. Dengan keterampilan memanfaatkan Google Classroom, SMP Pajajaran 1 Bandung masih dapat melaksanakan pembelajaran daring. Pembelajaran ini juga dapat menjadi pelengkap proses pembelajaran konvensional di saat normal setelah pandemi berakhir dan ada potensi menggeser hasil studi sebelumnya yang menyebutkan pembelajaran dengan platform Google Classroom tidak terlalu efektif.
\end{abstract}

Keyword: Google Classroom, Pembelajaran Daring, Keefektifan.

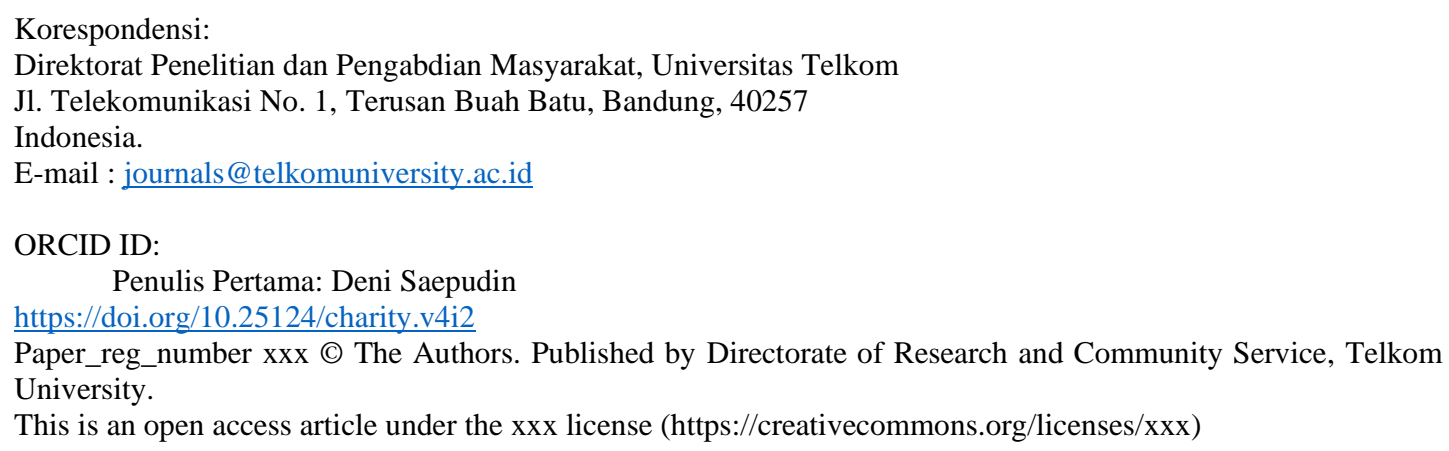




\section{Pendahuluan}

Saat pemerintah memutuskan kegiatan belajar dari rumah sejak pertengahan Maret 2020 sampai saat ini dikarenakan pandemi Covid-19, proses pengajaran di banyak sekolah mengalami kendala. Banyak guru mengalami kesulitan dalam mengelola pengajaran dan ujian di kelas dikarenakan belum siap dalam menggunakan memanfaatkan media daring. Ditambah lagi dengan beberapa keterbatasan seperti keterbatasan perangkat dan jaringan yang dialami baik oleh guru maupun murid. Oleh karena itu, proses pengajaran pada awal diberlakukannya belajar dari rumah berjalan kurang optimal.

Seiring berjalannya waktu, sekolah yang memiliki ketersediaan perangkat dan jaringan telekomunikasi (internet) yang cukup memadai, maka proses adaptasi pengajaran ke daring relatif lebih mudah dilakukan karena yang diperlukan hanya pembiasaan penggunaan platform daring, bahkan sebagian di antaranya masih dapat melakukan pembelajaran tatap muka sinkronus melalui fitur video conference.

Namun untuk sebagian sekolah di mana ketersediaan perangkat dan jaringan internet yang sangat terbatas maka ini menjadi tidak mudah untuk dilakukan. Dan hal ini terjadi salah satunya di SMP Pajajaran 1 Bandung. Agar kegiatan pengajaran dapat berjalan maka perlu dipikirkan

a. Bagaimana memilih platform yang tidak berbayar dan dapat digunakan oleh seluruh guru dan siswa?

b. Bagaimana mengoptimalkan platform tersebut untuk pengajaran dan evaluasi pengajaran?

\section{Google Classroom}

Google Classroom adalah salah satu ruang kelas virtual dalam jaringan yang memungkinkan peserta untuk berkomunikasi satu dengan yang lain, menyimak presentasi dan menonton video, berinteraksi dengan peserta lain, dan terlibat dengan sumber daya dalam kelompok [1]. Google classroom dapat digunakan secara gratis oleh setiap orang, dan karena dukungan kelengkapan fiturnya maka banyak dijadikan pilihan platform pembelajaran daring di banyak tempat di seluruh dunia.

Google Classroom dipandang sebagai salah satu platform terbaik untuk pengajaran daring karena menyediakan banyak fitur dan menjadikannya alat yang ideal untuk digunakan oleh guru dan siswa. Google Classroom dapat digunakan oleh siapa saja untuk kegiatan pendidikan dan menyediakan layanan seperti Gmail, Drive, dan Dokumen. 
Google Classroom dapat dijalankan pada PC/Laptop dan juga pada hp android sehingga memungkinkan diakses secara luas terutama oleh siswa yang memiliki perangkat secara terbatas. Penggunaan Google Classroom memudahkan guru untuk mengelola kelas, melakukan pengajaran asinkronus dan memberikan ujian baik secara sinkronus maupun asinkronus. Berdasarkan pertimbanganpertimbangan tersebut maka dipilihlah Google Classroom sebagai platform yang akan digunakan untuk pembelajaran daring di SMP Pajajaran 1 Bandung.

\section{Pelatihan Untuk Guru}

Penggunaan Google Classroom relatif mudah, namun tidak semua guru memahami penggunaannya karena tidak terbiasa mengeksplorasi sendiri. Untuk membantu mempercepat penguasaan Google Classroom untuk para guru, maka perlu dilakukan pengenalan dan pelatihan, agar memberikan gambaran penggunaannya. Setelah itu mereka dapat mencoba dan mengeksplorasinya secara mandiri.

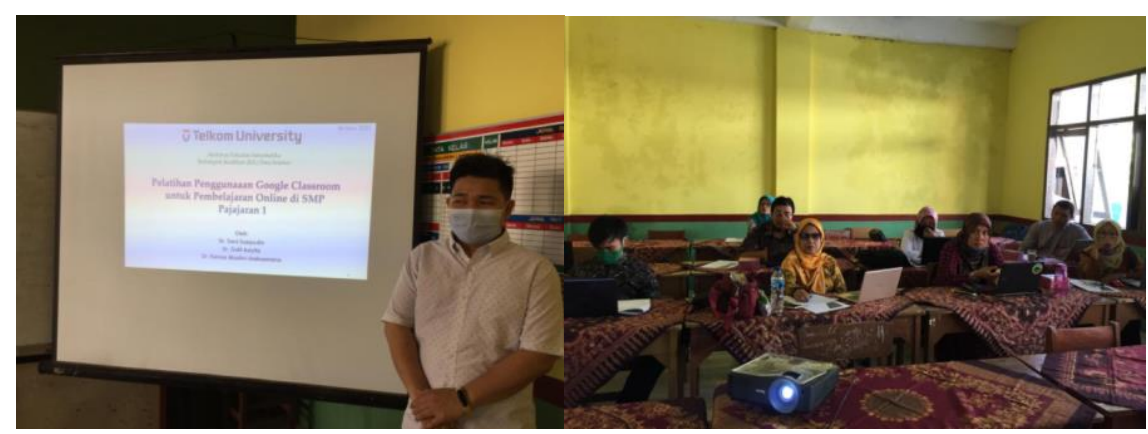

Gambar 1. Pelatihan Google Classroom untuk Guru di SMP Pajajaran 1 Bandung yang diikuti oleh 11 orang guru.

Setelah diperkenalkan Google Classroom dan diberikan contoh penggunaannya, hampir semua guru bisa memahami dan menggunakannya. Berikut adalah hasil survey pemahaman guru terhadap penggunaan Google Classroom.
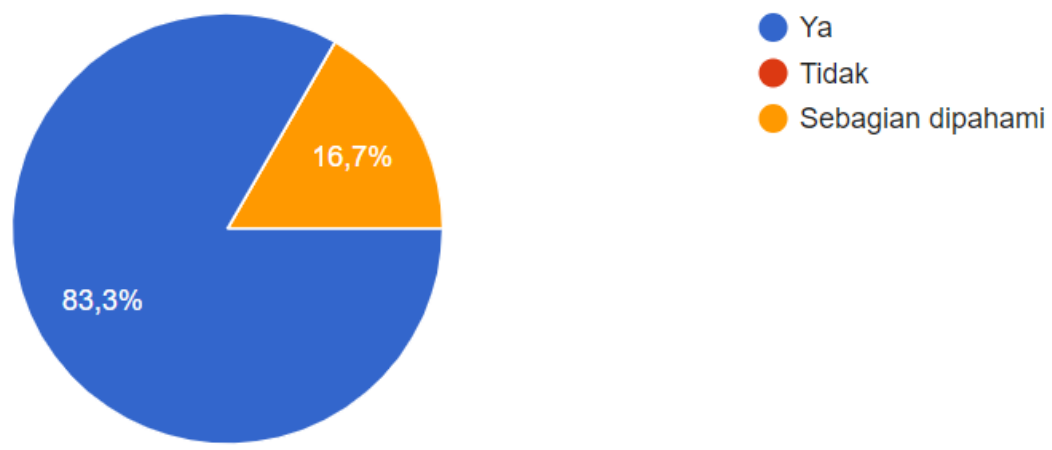

Gambar 2. Pemahaman penggunaan Google Classroom setelah pelatihan. 
Selanjutnya ingin diketahui apakah para guru akan menggunakan Google Classroom untuk pembelajaran. Hasil survey menunjukan bahwa lebih dari $60 \%$ para guru akan memanfaatkan Google Classroom untuk penyampaian materi dan ujian/tugas, dan sisanya menggunakan Google Classroom untuk ujian/tugas saja.

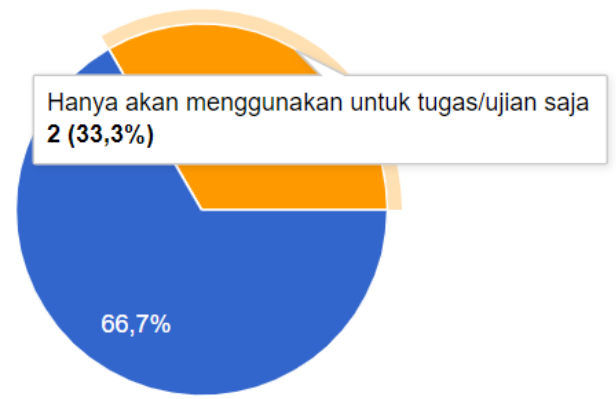

Ya..akan menggunakan baik dalam penyampaian materi maupun tugas/ ujian

Hanya akan menggunakan untuk penyampaian materi saja

- Hanya akan menggunakan untuk tugas/ ujian saja

Tidak akan menggunakan sama sekali baik penyampaian materi maupun tugas/ujian

Gambar 3. Rencana penggunaan Google Classroom dalam pengajaran.

\section{Efektivitas Google Classroom}

Pada tahun 2018, efektivitas penggunaan Google Classroom untuk pengajaran diteliti oleh Azhar dkk [2], hasil penelitian menunjukan bahwa menurut persepsi guru, pembelajaran dengan Google Classroom dinilai kurang efisien. Mereka memandang Google Classroom sebagai alat untuk mengelola dokumen dan pengelolaan kelas secara basic dan tidak berdampak signifikan pada metodologi pengajaran. Mereka menganggap bahwa kurang/tidak adanya kegiatan tatap muka menjadi alasan utama kurang efektifnya Google Classroom.

Penelitian yang dilakukan oleh Azhar dkk dilakukan jauh sebelum adanya pandemi Covid 19. Sebagaimana diketahui, adanya pandemi Covid 19 banyak mengubah persepsi dan model bisnis dan cenderung menggeser aktivitas masyarakat dari konvensional menjadi online. Adanya pandemi memaksa sebagian orang beralih ke online dan bukan tidak mungkin bahwa peralihan ini akan menjadi kultur baru yang bertahan ketika pandemi telah berlalu.

Sementara itu, Al-Maroof dkk [3] melakukan studi apa yang membuat persepsi guru atau murid bisa berbeda terhadap tingkat kegunaan dari Google Classroom. Hasil studi menunjukan bahwa persepsi kegunaan dan persepsi kemudahan penggunaan berpengaruh positif terhadap niat perilaku pengguna, yang pada gilirannya mempengaruhi penggunaan Google Classroom.

Bondarenko dkk [4] melaporkan hasil studinya mengenai pemanfaatan Google Classroom untuk blended learning untuk pelajaran Geografi. Hasil studi menunjukan bahwa banyak keuntungan yang diperoleh, yaitu terbentuknya interaksi real-time dari mata pelajaran, ada dukungan pedagogis yang konstan, meningkatkan alat peraga dalam pembelajaran, mendukung pemikiran kritis, mendukung siswa lebih dekat dengan ICT. Di sisi lain, penggunaan Google Classroom dinilai memiliki kekurangan di antaranya rendahnya motivasi dan tingkat kesiapan mereka di kelas, dukungan materi dan teknis yang kurang, kebutuhan akan dukungan pedagogis di luar kelas dan lain-lain. 
Secara umum dari studi yang dilakukan terhadap keefektifan Google Classroom untuk pembelajaran, terlihat bahwa Google Classroom dinilai tidak terlalu efektif dan belum menyamai keefektifan pengajaran tatap muka. Namun perlu diingat bahwa studi ini dilakukan sebelum terjadinya pandemi Covid-19 yang mendorong dengan sangat kuat penggunaan media daring dalam pengajaran, dan salah satunya adalah Google Classroom. Oleh karena itu sangat mungkin kedepannya hasil studi ini akan bergeser pasca pandemi Covid-19.

\section{Prospek Penggunaan Google Classroom}

Untuk melihat prospek penggunaan Google Classroom untuk pembelajaran setelah pademi Covid-19, para guru diminta untuk memberikan pendapat mengenai rencana mereka menggunakan Google Classroom, minimal sebagai pelengkap pembelajaran tatap muka. Hasil survey menunjukan bahwa mayoritas guru merencanakan menggunakan Google Classroom untuk pembelajaran pelengkap di samping pembelajaran tatap muka.

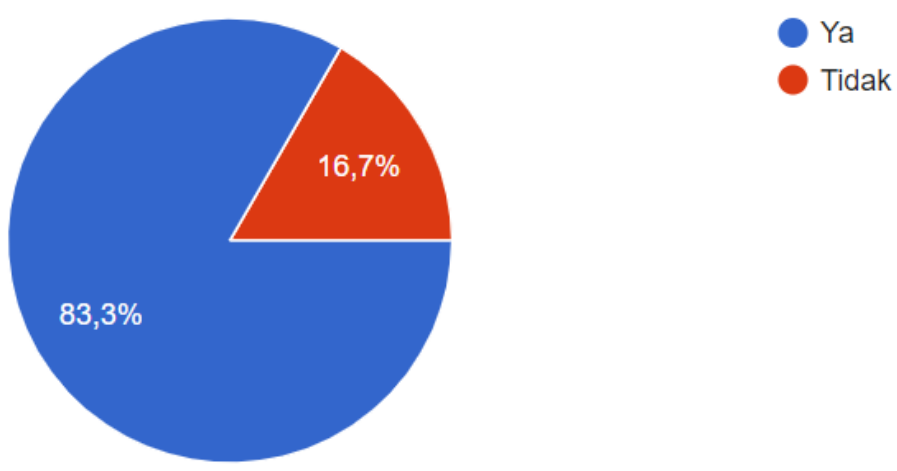

Gambar 4. Apakah guru berencana menggunakan Google Classroom sebagai pelengkap pengajaran di masa setelah pandemi Covid 19.

\section{Kesimpulan}

- Dari penelaahan literatur diketahui bahwa studi tentang keefektifan Google Classroom untuk pembelajaran dinilai tidak terlalu menggembirakan. Namun hasil ini mungkin akan bergeser setelah terjadinya pandemi Covid-19 di mana penggunaan Google Classroom secara meluas dilakukan bahkan oleh sekolah yang mengalami keterbatasan perangkat dan jaringan seperti SMP Pajajaran 1 Bandung.

- Pada waktu mendatang, penggunaan platform untuk pembelajaran daring yang bebas biaya dan dapat diakses secara meluas dengan perangkat yang terbatas sangat diperlukan, khususnya untuk sekolah-sekolah di Indonesia yang masih banyak mempunyai keterbatasan. 


\section{DAFTAR PUSTAKA}

[1] Iftakhar, Shampa. "Google classroom: what works and how." Journal of Education and Social Sciences 3.1 (2016): 12-18.

[2] Azhar, Kaukab Abid, and Nayab Iqbal. "Effectiveness of Google classroom: Teachers' perceptions." Prizren Social Science Journal 2.2 (2018): 52-66.

[3] Al-Maroof, Rana A. Saeed, and Mostafa Al-Emran. "Students acceptance of Google classroom: An exploratory study using PLS-SEM approach." International Journal of Emerging Technologies in Learning (iJET) 13.06 (2018): 112-123.

[4] Bondarenko, Olha, Svitlana Mantulenko, and Andrey Pikilnyak. "Google classroom as a tool of support of blended learning for geography students." CEUR Workshop Proceeding, Vol 2257 (2019). 